\title{
Regular Energetics at Conjugated Electrolyte/Electrode Modifier for Organic Electronics and Their Implications of Design Rules
}

Qinye Bao, Xianjie Liu, Ergang Wang, Junfeng Fang, Feng Gao, Slawomir Braun and Mats Fahlman

\section{Linköping University Post Print}

\section{Tweet}

N.B.: When citing this work, cite the original article.

Original Publication:

Qinye Bao, Xianjie Liu, Ergang Wang, Junfeng Fang, Feng Gao, Slawomir Braun and Mats Fahlman, Regular Energetics at Conjugated Electrolyte/Electrode Modifier for Organic Electronics and Their Implications of Design Rules, 2015, Advanced Materials Interfaces, (2), 12, 1-6.

http://dx.doi.org/10.1002/admi.201500204

Copyright: Wiley: 12 months

http://eu.wiley.com/WileyCDA/

Postprint available at: Linköping University Electronic Press http://urn.kb.se/resolve?urn=urn:nbn:se:liu:diva-118917 


\section{WILEY-VCH}

DOI: $10.1002 /(($ please add manuscript number $))$

\section{Article type: Communication}

\section{Regular Energetics at Conjugated Electrolyte/Electrode Modifier for Organic Electronics and Their Implications on Design Rules}

Qinye Bao*, Xianjie Liu, Ergang Wang, Junfeng Fang, Feng Gao, Slawomir Braun and Mats Fahlman

Q. Bao, Dr. X. Liu, Dr. S. Braun, Prof. M. Fahlman

Divsion of Surface Physics and Chemistry, IFM, Linköping University SE-58183 Linköping, Sweden

Email: qinba@ifm.liu.se

Dr. E. Wang

Department of Chemistry and Chemical Engineering, Chalmers University of Technology, SE-41296, Göteborg, Sweden

Prof. J. Fang

Ningbo Institute of Material Technology and Engineering, Chinese Academy of Science, Ningbo, Zhejiang 315201, PR China

Dr. F. Gao

Biomolecular and Organic Electronics, IFM, Linköping University SE-58183 Linköping, Sweden

Keywords: conjugated electrolyte, electrode modifier, energetics, organic electronics

\section{Introduction}

Polymer-based electronic devices such as transistors, light emitting diodes and photovoltaic cells are considered to be an attractive technology with the potential advantages of high throughput, low manufacturing cost, light weight, and mechanical flexibility. ${ }^{[1-3]}$ All such stacked devices contain several interfaces, e.g. electrode/organic and/or organic/organic, that significantly play a role in the device performance. Consequently much effort has been invested in tailoring electrodes using interlayers to optimize charge injection/extraction. ${ }^{[4-11]}$ 


\section{WILEY-VCH}

Recent reports have demonstrated that conjugated electrolytes (CEs) containing a $\pi$ delocalized backbone and pendant ionic groups are very efficient charge injection/extraction interlayers for device operation, ${ }^{[12-14]}$ as they can effectively tune the work function of metal electrodes. ${ }^{[12,15]}$ Furthermore, the ionic groups render the CEs soluble in polar solvents, allowing the subsequent coating process of the organic layer with no damage to or intermixing with the underlying semiconducting polymer layer that typically is deposited with non-polar solvents. ${ }^{[16]}$ Finally, since CEs feature $\pi$-conjugated backbones they are reasonably efficient at transporting charge so that the relatively thick films obtained in printing processes could in theory be used without significant loss in device efficiency. The use of CEs for interface engineering in (printed) polymer electronics hence is very attractive and much effort consequently has been invested into understanding the mechanisms for non-conjugated and conjugated electrolyte-based work function modification resulting in several different models recently being presented. ${ }^{[15,17-24]}$ One approach sets the work function modification by the electrolyte as a pure interface effect where one of the charged species can achieve a more intimate contact with the electrode surface by e.g. being more mobile than the counter charge. ${ }^{[18]}$ When the ions are located close to the interface, the Ion $^{+}$and Ion $^{-}$can interact with their respective induced image charge on the substrate, and since one of the ion species are more mobile, e.g. Ion $^{+}$, those ions will move closer to the substrate and as a consequence form a "double dipole step" up-shifting the work function. ${ }^{[18]}$ If the Ion $^{-}$is more mobile, a double dipole step down-shifting the work function instead is formed. This effect only occurs at the interface and hence is film thickness independent. It also occurs independently of the substrate work function, but the size of the double dipole step is generally larger for metal electrodes than semiconductors (and $\sim$ negligible for insulator substrates). ${ }^{[18]}$ For systems where both charges are equally mobile/immobile, e.g. zwitterion-based electrolytes, (partial) alignment of the ion-containing side chains through either interaction with the electrode at the 


\section{WILEY-VCH}

interface or (bulk) realignment through an electric field will create dipole-induced potential steps. ${ }^{[21-23]}$

Besides the work function modification through the ions of the electrolyte, for CEs additional shifts in the vacuum level for the CE/electrode contact can be expected as the interface energetics of $\pi$-conjugated molecules and polymers coated onto metal substrates often deviate from simple vacuum level alignment. ${ }^{[25],[26]}$ In fact, the energetics of the neutral $\pi$-conjugated organic semiconductor at weakly metal/organic and organic/organic interfaces obtained from solution based printing usually follow the trend predicted by the so-called integer charge transfer (ICT) model, i.e. three distinct regimes where the Fermi level is either pinned to negative/positive interface polarons or vacuum level alignment holds, see Fig 1. ${ }^{[27-29]}$ The Fermi level pining is caused by spontaneous charge transfer across the interface via tunneling when the underlying substrate is greater (lower) than the energy required to oxidize (gained form reducing) a molecule at the interfaces. The most easily oxidized/reduced sites adjacent to the interface hence will be "used up" forming so-called ICT states until enough charge has been transferred across the interface to create a potential step that equilibrates the Fermi level. The energy where the Fermi level is subsequently pinned is referred to as EICT+,depending on if it is positive or negative polarons that are being created and several approaches recently have been developed to calculate the pinning energies of organic semiconductors. ${ }^{[30-33]}$ Note that the ICT states are essentially polarons interacting with the transferred charge (or image charge) on the other side of the interface. This additional energy, not present for bulk polarons, and variation in intermolecular order typically cause the ICT state distribution to be different than the bulk polaron distribution, ${ }^{[26]}$ see Fig. 1.

As CEs feature both $\pi$-conjugated electronic structures and ions it is reasonable to expect that CE/electrode energetics can be described by combination of the ICT model and models 


\section{WILEY-VCH}

based on non-conjugated electrolytes. We explore this hypothesis using photoemission spectroscopy, with the aim to propose a general model for energy level alignment involving CE interlayers. As the work function modification is strongly dependent on the ionic functionality, ${ }^{[34]}$ we use a CE series with various ionic groups, including cationic poly ${ }^{\left[{ }^{[16-}\right.}$ fluorene)-alt-2,7-(9,9-dioctylfluorene)]

$(\mathbf{P F N})$, poly[2,3-bis(3'-(8"-(N,N-dimethylamino)octyloxy)phenyl)quinoxaline-5,8-diyl-alt-thiophene-2,5-diyl] (TQm8-N), poly[(9,9bis(3'-((N,N-dimethyl)-N-ethylammonium)-propyl)-2,7-fluorene)-alt-2,7-(9,9-dioctyl-

fluorene)] (PFNBr), anionic poly [3-(5-carboxypentyl)thiophene-2,5-diyl] (P3CBT) and zwitterionic poly[(9,9-bis((N- (4-sulfonate-1-butyl)-N,N-dimethylammonium)-ethanyl)-2,7fuorene)-alt-2,7-(9,9-dioctylfuorene), $\mathbf{P}\left(\mathbf{N S O}_{3}\right)_{2}$. Fig. 2 shows their corresponding chemical structures. The resulting energetics model further unravels the design rule for CE/electrode modifier to achieve the smallest charge injection/exaction barrier and break through the current thickness limitation.

\section{Results and Discussion}

Fig.3a displays the dependences of the work function of various CE films spin-coated on top of electrodes, $\Phi_{C E / e l}$, on the work function of the bare electrodes, $\Phi_{e l}$. Two distinct slope $\mathrm{S}$ $=0$ and $\mathrm{S}=1$ regions are clearly observed, following the general ICT model behavior. For PFN films, when $\Phi_{e l}$ is larger than $3.95 \mathrm{eV}$, the Fermi level is pinned to $3.8 \mathrm{eV}$. When $\Phi_{e l}$ is smaller than $3.95 \mathrm{eV}, \Phi_{C E / e l}$ is equal to $\left(\Phi_{e l}-0.15\right) \mathrm{eV}$ with a displacement of $-0.15 \mathrm{eV}$ away from Schottky-Mott limit in comparison with the $S=1$ (ii) region of the ideal ICT curve in Fig. 1. The same trend is also found for the other CEs. TQm8-N shifts $\sim-0.15 \mathrm{eV}$ due to the same structure of ionic functionality as that of PFN. The energy shift of PFNBr and zwitterionic $\mathrm{P}\left(\mathrm{NSO}_{3}\right)_{2}$ films correspond to -0.21 and $-0.42 \mathrm{eV}$, respectively, and the substrate independent work function of the CE/electrode in region (iii) of the ICT curve, hereafter denoted $\mathrm{E}_{\text {pin+ }}$, is 


\section{WILEY-VCH}

estimated as 4.02 and $3.23 \mathrm{eV}$ as shown in Fig. 3a. For the anionic P3CBT film, an upshift energy of $+0.33 \mathrm{eV}$ occurs with the $\mathrm{E}_{\text {pin+ }}$ as high as $4.57 \mathrm{eV}$. The full energetics of the $\mathrm{CE}$ series is summarized in Table 1.

The findings are surprisingly similar to recent results on interfaces featuring molecules with intrinsic dipoles ${ }^{[35]}$ and for molecule-doped conjugated polymer/electrode interfaces. ${ }^{[36]}$ In the former case, a potential step is induced from (partial) ordering of the molecular dipoles. In the latter case, one of the charged species in the doped organic semiconductor film is more mobile, typically the polaron on the host molecule as it tends to be more delocalized than the counter charge on the dopant molecule, and the more mobile charge hence can achieve a more intimate contact with the substrate giving rise to the so-called double dipole step. ${ }^{[18,36]}$ To test if the shift of the regular ICT curves obtained for the CEs can be explained by the same mechanisms, we first follow the UPS spectra evolution of PFNBr as function of thickness, see Fig. 3b. As noted, an image-charge-induced double dipole step occurs only at the interface and hence there should be no thickness dependence of the size of the potential step. ${ }^{[18]} \mathrm{We}$ choose $\mathrm{AlOx} / \mathrm{Al}$ with $\Phi_{e l}$ of $3.85 \mathrm{eV}$ as substrate so as to locate the experiment in the $\mathrm{S}=1$ region and avoid contribution from integer charge transfer. In Fig. $3 b$ it is clear that the size of the work function shift is independent of film thickness and the $\Phi_{C E / e l}$ of PFNBr is held constant at $3.65 \mathrm{eV}$ (Fig. 3c). The $\Phi_{C E / e l}$ of the anionic P3CBT also exhibits thicknessindependence in the $S=1$ region (see Fig. S2). The origin of the potential step shifting the ICT curve can thus be attributed to image-charge-induced double dipoles. In PFN, TQm8-N and $\mathrm{PFNBr}$, the migrated ions are negatively charged $\mathrm{OH}^{-}$and $\mathrm{Br}^{-}$resulting in down-shift potential step, whereas P3CBT with its mobile protons should produce an up-shift potential step, all in agreement with the experimental results. The $\mathrm{P}\left(\mathrm{NSO}_{3}\right)_{2}$ does not feature ionic species of differing mobility, but a negative potential step at the $\mathrm{P}\left(\mathrm{NSO}_{3}\right)_{2}$ interfaces attributed to electrostatic realignment of the dipolar zwitterionic side chains instead is expected, ${ }^{[21]}$ and is 


\section{WILEY-VCH}

indeed observed in our results and in analogy with the results on molecules with intrinsic dipoles. ${ }^{[35]}$ The results thus enable us to propose a general model for describing the energetics of CE/electrode interfaces:

(i) Equilibration of the Fermi level due to oxidation/reduction of $\pi$-delocalized backbone at interface as per the ICT model

Additionally (ii) a constant interfacial potential step induced by ion migration or side chain electrostatic realignment.

The effect of the image charge induced double dipole step $\Delta_{\mathrm{D}}$ is illustrated in Fig. 4. The solid line in Fig. 4a represents the "ideal" ICT curve of conjugated organic semiconductor before ionic functionality or a CE when $\Delta_{\mathrm{D}}$ is zero ( the case of insulator substrates). For cationic CEs on conducting substrates, the $\Delta_{\mathrm{D}}$ down-shifts the ICT curve, yielding lower CE/electrode work functions over the whole range, and anionic CEs undergo an up-shift then resulting in higher CE/electrode work functions compared to the neat electrode. Another consequence of the model is that same effective pinning energies of a $\mathrm{CE} /$ metal electrode system can be achieved by either a cationic acceptor CE or by an anionic CE, donors having lower pinning energies than acceptors. The anionic CE/electrode ICT curve would have its onset shifted to lower energies compared to an imaginary ideal ICT curve for those pinning energies, whereas the cationic CE/electrode ICT curve would seemingly be shifted to higher onset energies, see Fig. 4b. The ionic functionality thus enables tuning of both the effective CE/electrode work function and the on sets of the (ii) and (iii) parts of the ICT regimes!

We now discuss the implications of our model for electrode modifier design. As can be seen from Fig. 4, cationic CE/electrodes are ideal for achieving low work function contacts as there will be a rigid down-shift of the vacuum level from the double dipole. For thin $\mathrm{CE}$ interlayers where charges tunnel through from the electrode into the organic semiconductor (OSC) film, the lowest work function achievable is limited by the negative pinning energy of 


\section{WILEY-VCH}

the CE (region (i) of the ICT curve), in turn a function of the ICT- energies of the CE and the size of the double dipole potential step $\Delta_{\mathrm{D}}$. The highest work function achievable is limited by the positive pinning energy of the CE (region (iii) of the ICT curve), in turn a function of the ICT+ energies of the CE and the size of the double dipole potential step $\Delta_{\mathrm{D}}$. By choosing a CE system featuring a "donor" backbone which will have ICT- and ICT+ energies relatively close to the vacuum level and maximizing $\Delta_{\mathrm{D}}$ through the design of the ion-containing side chains, an optimal electron-injecting interlayer is obtained. (In practice, when such a system is coupled to an inert metal such as e.g. Ag, the resulting metal/CE contact will be in the (ii) or (iii) regime, so the ICT- energies of the CE are of less importance). The situation changes for the case of thick CE interlayers where the electrons are injected into the $\mathrm{CE}$ and subsequently transported to the CE/OSC interface. Efficient electron injection into the $\mathrm{CE}$ from the electrode is achieved for region (i) of the ICT curve, so it then follows that cationic CEs for thick interlayer applications ideally should be synthesized from an acceptor-type $\pi$-conjugated backbone or molecule. As is illustrated in Fig. 4a, the dipole step $\Delta_{\mathrm{D}}$ induced by the cationic functionality to the conjugated OSCs down-shifts the negative and positive pinning energies and also effectively shifts the onset of regions (ii) and (iii) to higher electrode work functions, enabling higher (more inert) work function electrodes to be used in forming a pinned contact.

Analogously, anionic CEs are then ideal for serving as hole injection/extraction interlayers as the double dipole step from the anionic functionality will up-shift the work function. For the thin CE interlayer case, the highest work function achievable is limited by the positive pinning energy of the CE (region (iii) of the ICT curve), in turn a function of the ICT+ energies of the CE and the size of the double dipole potential step $\Delta_{\mathrm{D}}$. The lowest work function achievable is limited by the negative pinning energy of the CE (region (i) of the ICT curve), a function of the ICT- energies of the CE and the size of the double dipole potential 


\section{WILEY-VCH}

step $\Delta_{\mathrm{D}}$. By choosing a CE system featuring an "acceptor" backbone which will have ICT+ (and ICT-) energies relatively deep compared to the vacuum level and maximizing $\Delta_{\mathrm{D}}$ through the design of the ion-containing side chains, an optimal hole-injecting interlayer is obtained. Again, the use of inert metals typically will place the electrode/CE contact in region (ii) or (iii). For thick $\mathrm{CE}$ interlayers where the holes are injected into the $\mathrm{CE}$ and subsequently transported to the CE/OSC interface, efficient hole-injection into the $\mathrm{CE}$ from the electrode is achieved for region (iii) of the ICT curve. It then follows that anionic CEs for thick interlayer applications ideally should be synthesized from a donor-type $\pi$-conjugated backbone or molecule. As illustrated in Fig. 4b, inclusion of anionic functionality to the conjugated OSCs up-shifts the negative and positive pinning energies and also shifts the onset of region (ii) and region (iii) to lower electrode work functions due to the $\Delta_{D}$. Hence, a (cheaper) lower work function electrode can thus be used to obtain an Ohmic hole injecting contact into the CE.

Note that though cationic CEs are always best for electron-injecting interlayers and anionic CEs are best for hole-injecting interlayers, the choice of $\pi$-conjugated backbone will depend on if the interlayer is thin or thick in the device (Fig.S3). Further note that designing the electrode/CE/OSC system so that pinning to the $\mathrm{ICT}^{+} / \mathrm{ICT}^{-}$states of the OSC are achieved not only reduces the hole-injection barrier $\left(\Phi_{h, \text { barrier }}\right) /$ electron injection barrier $\left(\Phi_{e, \text { barrier }}\right)$, but also increases the carrier concentration and suppresses carrier recombination at the contact as well as the sequential dark current in OPVs, as is confirmed by device results. ${ }^{[11]}$

From the proposed model it is easy to understand why many of the current cationic CEs are unsuitable as thick electron injecting/transporting layers. Since the $\pi$-delocalized backbones of $\mathrm{PFN}, \mathrm{PFNBr}$ and $\mathrm{P}\left(\mathrm{NSO}_{3}\right)_{2}$ are intrinsically donors, the CE/electrode interface typically winds up in the (iii) region of the ICT curve when using inert metal electrodes, yielding the largest possible $\Phi_{e, \text { barrier }}$ for the CE, see Fig. 1c, which is why the thickness in OPVs is limited 


\section{WILEY-VCH}

typically to less than $5 \mathrm{~nm}^{[21,22,37,38]}$. Acceptor cationic CEs should on the other hand be near ideal for designing electron injecting CE/electrode contacts, as the acceptor nature of these materials enable pinning to the $\mathrm{ICT}^{-}$states even for moderately high work function electrodes $\left(<4.6 \mathrm{eV}\right.$ or so, Table 2). Pinning in the (i) region of the ICT curve ensures the lowest $\Phi_{e, \text { barrier }}$ (see Fig. 1c) and hence efficient electron injection and transport even for thicker CE layers, as demonstrated for e.g. fullerene-based electrolyte, e.g., $\mathrm{C}_{60}-\mathrm{N}^{[39]} \mathrm{C}_{60}-\mathrm{SB}^{[39]}$ and BisOMeFPI. ${ }^{[24]}$ In the same way, anionic CEs should have donor $\pi$-delocalized backbones, e.g. P3CBT, ${ }^{[40]}$ PCPDTBT-SO ${ }_{3}-\mathrm{K}^{[41]}$ and $\mathrm{PCPDTPhSO}_{3}-\mathrm{Na}^{[42]}$, enabling pinning in the (iii) region under the moderate $\Phi_{e l}$ and the lowest $\Phi_{h, \text { barrier }}$ at the CE/electrode interface regardless of thickness (Table 2 and Fig. S4).

In conclusion, a general model for energetics at conjugated electrolyte/electrode modifier is proposed: (i) equilibration of the Fermi level due to oxidation/reduction of $\pi$-delocalized backbone at interface as per the integer charge transfer model in combination with (ii) an additional interface dipole step induced by ion migration or side chain electrostatic realignment. The model further reveals how to design conjugated electrolyte/electrode modifier to achieve the smallest charge injection/extraction barrier combined with optimized charge transport. For thick charge transporting interlayers, donor $\pi$-conjugated anionic CEs and acceptor $\pi$-conjugated cationic CEs are optimal as anode and cathode, respectively, breaking through the current thickness limitation. In contrast, for thin tunneling interlayers, acceptor $\pi$-conjugated anionic CEs and donor $\pi$-conjugated cationic CEs are optimal as anode and cathode. 


\section{WILEY-VCH}

\section{Materials and Methods}

The cationic PFN and PFNBr were obtained from Lumtec, and the cationic P3CBT was purchased from Rieke Metal. TQm8-N and $\mathrm{P}\left(\mathrm{NSO}_{3}\right)_{2}$ were synthesized as the previous reports. ${ }^{[16,22]}$ Films were spin coated on various conducting substrate with a broad range of work function from 3.5 to $5.7 \mathrm{eV}$ to create interfaces, then directly transferred into the load lock chamber of the ultrahigh vacuum (UHV) system for UPS measurement so as to detect the relation between the work function of $\mathrm{CE} /$ electrode and the work function of bare electrode. Sets of conducting substrates were chose according to the previous reports. ${ }^{[28,36]}$ All substrates are cleaned by sonication in acetone and isopropyl before spin coating. The different thickness films are achieved by tuning spin speeds and solution concentrations. The monolayer film is roughly judged by the evolution of the frontier electronic features. The Photoemission spectroscopy measurements were carried out in a home UHV surface analysis including a sample analysis chamber with the base pressure of $2 \times 10^{-10} \mathrm{mbar}$, and the spectra were recorded with a Scienta-200 hemispherical analyzer. UPS with He I $21.22 \mathrm{eV}$ as the excitation source was to characterize the work function derived from the secondary electron cut-off and the frontier electronic features with an error margin of $\pm 0.04 \mathrm{eV}$. XPS measurement was performed using monochromatized $\mathrm{Al} \mathrm{Ka}$ with $h v=1486.6 \mathrm{eV}$. All measurements were calibrated by referencing to Fermi level and $\mathrm{Au} 4 \mathrm{f}_{7 / 2}$ peak position of the $\mathrm{Ar}^{+}$ion sputter-clean gold foil.

Additional information: Supporting information is available.

Acknowledgements: This work is sponsored by the EU project SUNFLOWER of FP7 cooperation programme, grant No. 287594, the Swedish Research Council project grant No. 2013-4022 and No. 2011-3984, the Swedish Foundation for Strategic Research and the Göran Gustafsson Foundation for Research in Natural Sciences and Medicine. The Swedish 


\section{WILEY-VCH}

Research Council Linnaeus grant LiLi-NFM and the Advanced Functional Materials Center at Linköping University are also gratefully acknowledged.

\section{References}

1. T. Kawase, H. Sirringhaus, R. H. Friend, and T. Shimoda, Adv. Mater. 2001, 13, 1601.

2. J. H. Burroughes, D. D. C. Bradley, A. R. Brown, R. N. Marks, K. Mackay, R. H. Friend, P. L. Burn, and A. B. Holmes, Nature 1990, 348, 352.

3. L. T. Dou, J. B. You, J. Yang, C. C. Chen, Y. J. He, S. Murase, T. Moriarty, K. Emery, G. Li, and Y. Yang, Nat. Photon. 2012, 6, 180.

4. A. Guerrero, S. Chambon, L. Hirsch, and G. Garcia-Belmonte, Adv. Funct. Mater. 2014, 24, 6234.

5. T.-H. Lai, S.-W. Tsang, J. R. Manders, S. Chen, and F. So, Materials Today 2013, 16, 424.

6. Z. Q. Xu, J. Li, J. P. Yang, P. P. Cheng, J. Zhao, S. T. Lee, Y. Q. Li, and J. X. Tang, Appl. Phys. Lett. 2011, 98.

7. Y. Zhou, C. Fuentes-Hernandez, J. Shim, J. Meyer, A. J. Giordano, H. Li, P. Winget, T. Papadopoulos, H. Cheun, J. Kim, M. Fenoll, A. Dindar, W. Haske, E. Najafabadi, T. M. Khan, H. Sojoudi, S. Barlow, S. Graham, J. L. Bredas, S. R. Marder, A. Kahn, and B. Kippelen, Science 2012, 336, 327.

8. H. Ma, H. L. Yip, F. Huang, and A. K. Y. Jen, Adv. Funct. Mater. 2010, 20, 1371.

9. Q.-Y. Bao, J.-P. Yang, J.-X. Tang, Y. Li, C.-S. Lee, and S.-T. Lee, Org. Electron. 2010, 11, 1578.

10. L. M. Chen, Z. Xu, Z. R. Hong, and Y. Yang, J. Mater. Chem. 2010, 20, 10947.

11. T. B. Yang, M. Wang, C. H. Duan, X. W. Hu, L. Huang, J. B. Peng, F. Huang, and X. Gong, Energ. Environ. Sci. 2012, 5, 8208.

12. C. V. Hoven, A. Garcia, G. C. Bazan, and T.-Q. Nguyen, Adv. Mater. 2008, 20, 3793.

13. A. Garcia, R. C. Bakus, 2nd, P. Zalar, C. V. Hoven, J. Z. Brzezinski, and T. Q. Nguyen, J. Am. Chem. Soc. 2011, 133, 2492.

14. J. Kim, D. Khim, R. Kang, S. H. Lee, K. J. Baeg, M. Kang, Y. Y. Noh, and D. Y. Kim, ACS Appl. Mater. Interfaces 2014, 6, 8108.

15. J. H. Seo and T. Q. Nguyen, J. Am. Chem. Soc. 2008, 130, 10042.

16. F. Huang, H. B. Wu, D. Wang, W. Yang, and Y. Cao, Chem. Mater. 2004, 16, 708.

17. H. B. Wu, F. Huang, Y. Q. Mo, W. Yang, D. L. Wang, J. B. Peng, and Y. Cao, Adv. Mater. 2004, 16, 1826.

18. S. van Reenen, S. Kouijzer, R. A. J. Janssen, M. M. Wienk, and M. Kemerink, $A d v$. Mater. Interfaces 2014, DOI: 10.1002/admi.201400189.

19. J. Park, C. V. Hoven, R. Q. Yang, N. S. Cho, H. B. Wu, T. Q. Nguyen, and G. C. Bazan, J. Mater. Chem. 2009, 19, 211.

20. C. Hoven, R. Yang, A. Garcia, A. J. Heeger, T. Q. Nguyen, and G. C. Bazan, J. Am. Chem. Soc. 2007, 129, 10976.

21. F. Liu, Z. A. Page, V. V. Duzhko, T. P. Russell, and T. Emrick, Adv. Mater. 2013, 25, 6868.

22. J. F. Fang, B. H. Wallikewitz, F. Gao, G. L. Tu, C. Muller, G. Pace, R. H. Friend, and W. T. S. Huck, J. Am. Chem. Soc. 2011, 133, 683.

23. B. H. Lee, I. H. Jung, H. Y. Woo, H.-K. Shim, G. Kim, and K. Lee, Adv. Funct. Mater. 2014, 24, 1100. 


\section{WILEY-VCH}

24. C. Z. Li, C. Y. Chang, Y. Zang, H. X. Ju, C. C. Chueh, P. W. Liang, N. Cho, D. S. Ginger, and A. K. Y. Jen, Adv. Mater. 2014, 26, 6262.

25. H. Ishii, K. Sugiyama, E. Ito, and K. Seki, Adv. Mater. 1999, 11, 972.

26. M. Fahlman, A. Crispin, X. Crispin, S. K. M. Henze, M. P. d. Jong, W. Osikowicz, C. Tengstedt, and W. R. Salaneck, J. Phys.: Condens. Mat. 2007, 19, 183202.

27. S. Braun, W. R. Salaneck, and M. Fahlman, Adv. Mater. 2009, 21, 1450.

28. Q. Bao, O. Sandberg, D. Dagnelund, S. Sandén, S. Braun, H. Aarnio, X. Liu, W. M. Chen, R. Österbacka, and M. Fahlman, Adv. Funct. Mater. 2014, 24, 6309.

29. Q. Y. Bao, X. J. Liu, S. Braun, and M. Fahlman, Adv. Energy. Mater. 2014, 4, DOI: 10.1002/aenm.201301272.

30. M. Bokdam, D. Cakir, and G. Brocks, Appl. Phys. Lett. 2011, 98, 113303.

31. L. Ley, Y. Smets, C. I. Pakes, and J. Ristein, Adv. Funct. Mater. 2013, 23, 794.

32. M. T. Greiner, M. G. Helander, W. M. Tang, Z. B. Wang, J. Qiu, and Z. H. Lu, Nat. Mater. 2012, 11.

33. M. Oehzelt, N. Koch, and G. Heimel, Nat. Commun. 2014, 5.

34. R. Kang, S. H. Oh, and D. Y. Kim, Acs Appl. Mater. Inter. 2014, 6, 6227.

35. L. Lindell, D. Çakır, G. Brocks, M. Fahlman, and S. Braun, Appl. Phys. Lett. 2013, 102, 223301.

36. Q. Y. Bao, X. J. Liu, S. Braun, F. Gao, and M. Fahlman, Adv. Mater. Interfaces 2014, DOI: 10.1002/admi.201400403.

37. Z. He, H. Wu, and Y. Cao, Adv. Mater. 2014, 26, 1006.

38. J. H. Seo, A. Gutacker, Y. M. Sun, H. B. Wu, F. Huang, Y. Cao, U. Scherf, A. J. Heeger, and G. C. Bazan, J. Am. Chem. Soc. 2011, 133, 8416.

39. Z. A. Page, Y. Liu, V. V. Duzhko, T. P. Russell, and T. Emrick, Science 2014, 346, 441.

40. W. W. Li, B. J. Worfolk, P. Li, T. C. Hauger, K. D. Harris, and J. M. Buriak, J. Mater. Chem. 2012, 22, 11354.

41. H. Q. Zhou, Y. Zhang, C. K. Mai, S. D. Collins, T. Q. Nguyen, G. C. Bazan, and A. J. Heeger, Adv. Mater. 2014, 26, 780.

42. H. Zhou, Y. Zhang, C. K. Mai, S. D. Collins, G. C. Bazan, T. Q. Nguyen, and A. J. Heeger, Adv. Mater. 2015.

43. S. Braun, Personal communication.

44. A. Crispin, X. Crispin, M. Fahlman, M. Berggren, and W. R. Salaneck, Appl. Phys. Lett. $2006,89$.

45. P. Sehati, S. Braun, L. Lindell, X. J. Liu, L. M. Andersson, and M. Fahlman, IEEE J. Sel. Top Quant. 2010, 16, 1718. 


\section{WILEY-VCH}

(a)

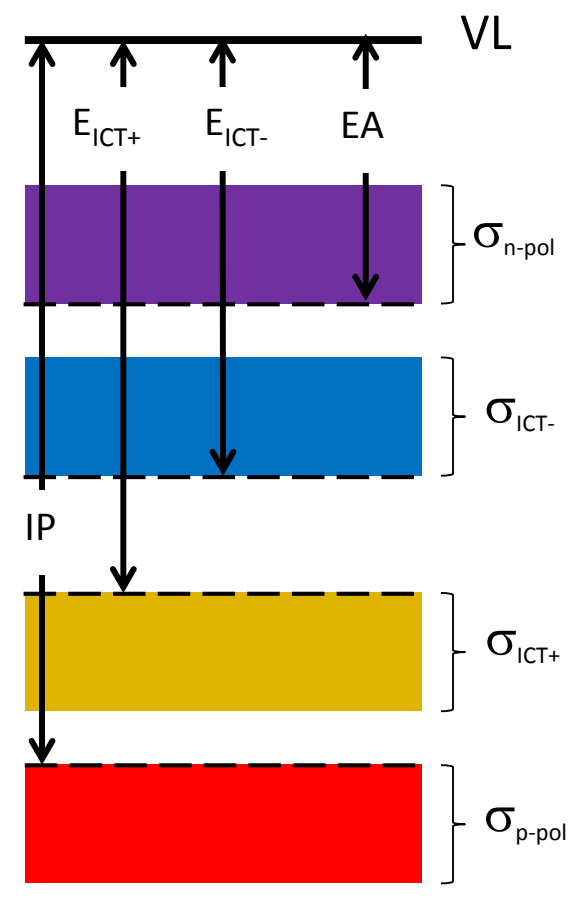

(b)

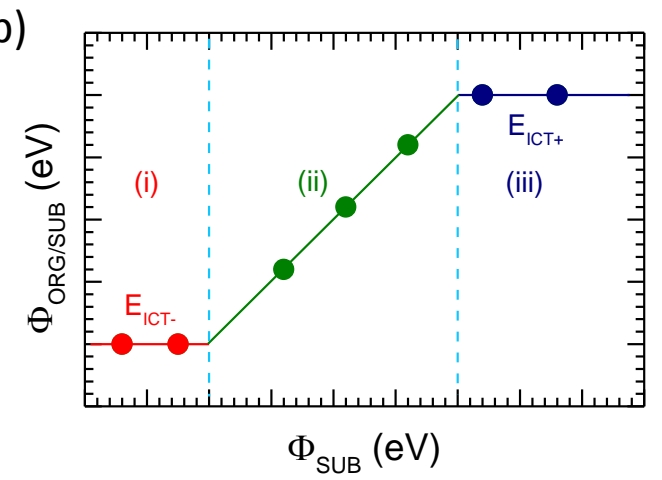

(c)

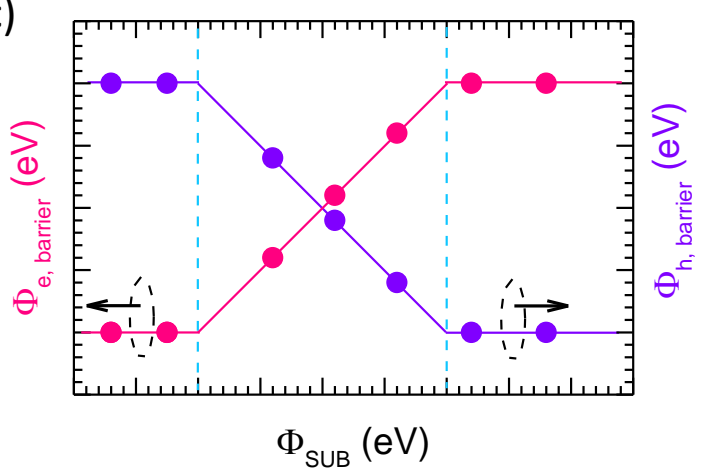

Fig.1 (a) General behavior of energy levels in an organic semiconductor film versus the vacuum level (VL): bulk n-polarons and their distribution $\sigma_{\mathrm{n}-\mathrm{pol}}$, bulk electron affinity (EA) defined as the n-polaron distribution edge, bulk p-polarons and their distribution $\sigma_{\mathrm{p} \text {-pol, }}$, bulk ionization potential (IP) defined as the p-polaron distribution edge, ICT energy distributions $\sigma_{\mathrm{ICT}+,-}$ and pinning energies $\left(\mathrm{E}_{\mathrm{ICT}+,-}\right)$ defined as the $\mathrm{ICT}_{+,-}$distribution edges. Note that the respective ICT and bulk polaron distributions partially may overlap depending on the e.g. the strength of the electrostatic interaction with the substrate upon forming an ICT state. (b) Energy level alignment regimes according to the ICT model (see text): work function of the (hybrid) organic interface ( $\left.\Phi_{\mathrm{ORG} / \mathrm{SUB}}\right)$ as a function of the substrate work function $\left(\Phi_{\mathrm{SUB}}\right)$. (c) Electron $\left(\Phi_{\mathrm{e}, \text { barrier }}\right)$ and hole $\left(\Phi_{\mathrm{h}, \text { barrier }}\right)$ injection barrier evolutions as a function of the $\Phi_{\mathrm{SUB}}$ : Electron Ohmic contact at OSC/substrate interface occurs in the (i) region, and hole Ohmic contact in the (iii) region. 


\section{WILEY-VCH}

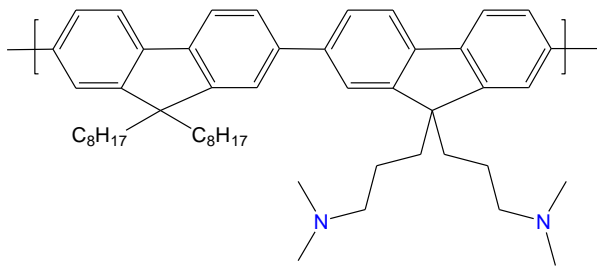

PFN

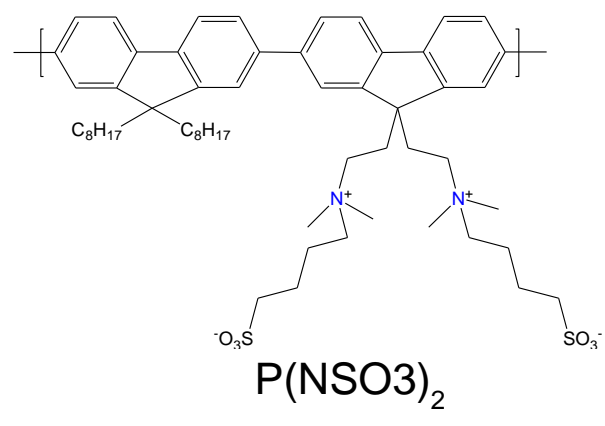

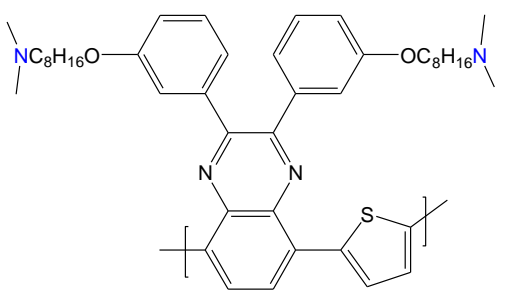

TQm8-N

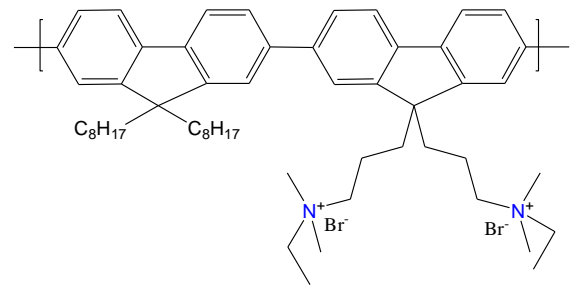

$\mathrm{PFNBr}$

Fig. 2 Chemical structures of the conjugated electrolyte series. 


\section{WILEY-VCH}

(a)

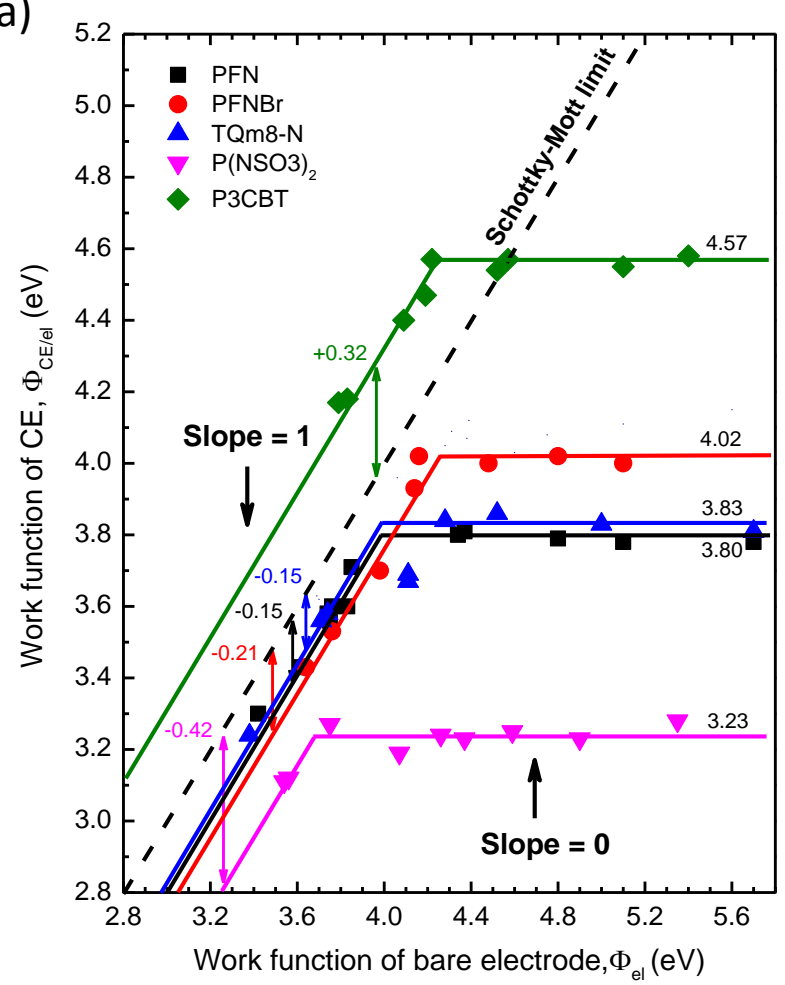

(b)

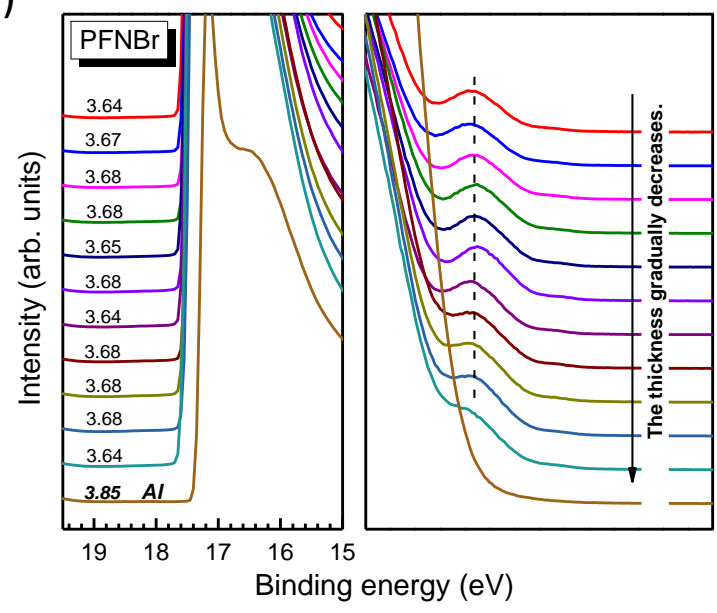

(c)

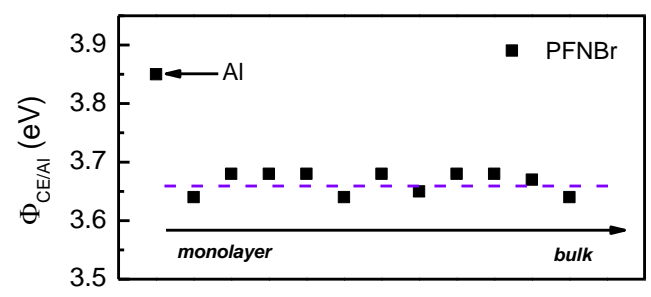

Fig. 3 (a) Dependence of the work function of various CE films spin-coated on the work function of the bare electrode. Distinct Fermi level pinning $(S=0)$ region and unpinned $(S=1)$ region with one energy shift away from Schottky-Mott limit are observed. (b) UPS spectra evolution both at the work function and the frontier electronic features of cationic PFNBr coated on $\mathrm{AlOx} / \mathrm{Al}$ located in $\mathrm{S}=1$ region as function of thickness from bulk to monolayer. (c) Plots of the work function of PFNBr/Al. 

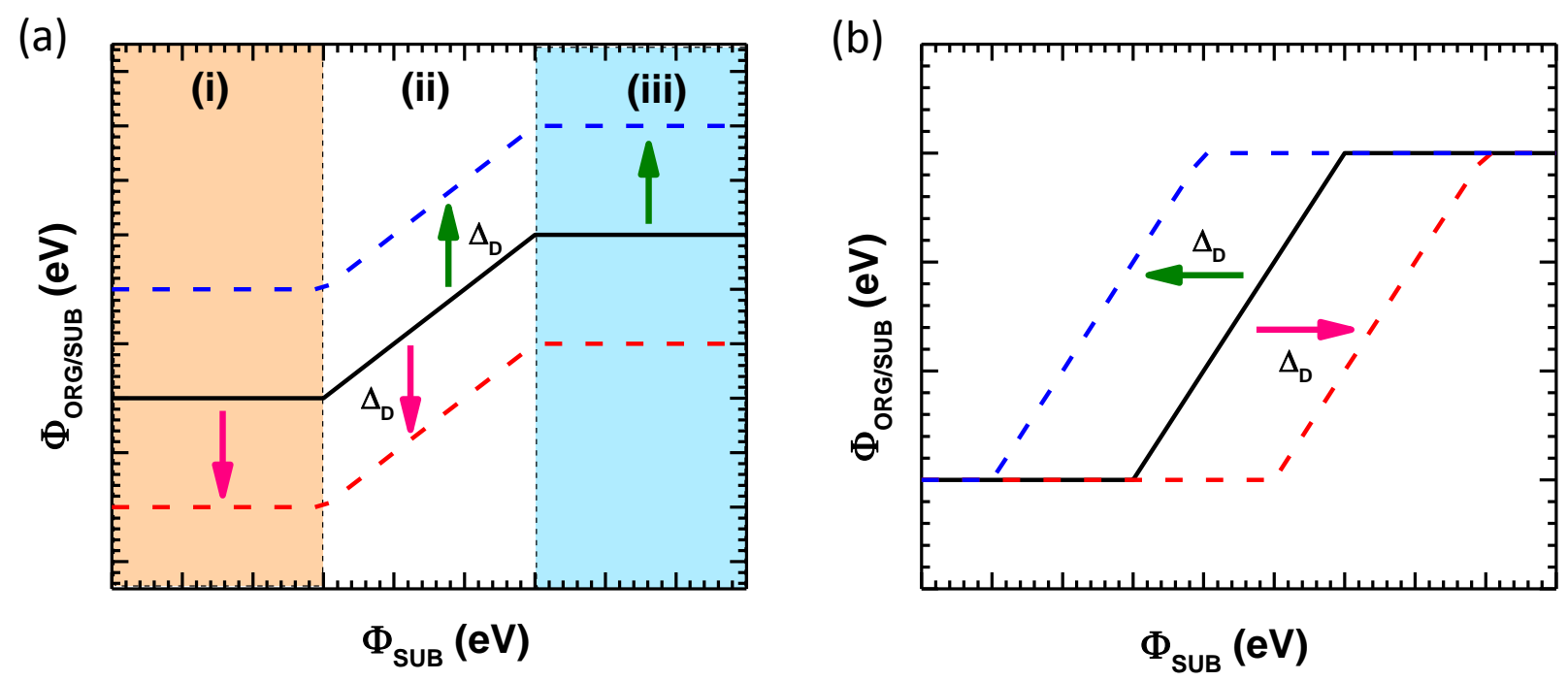

Fig. 4 (a) Shift of the "ideal” ICT curve (solid black line) for an anionic CE (blue dashed line) and a cationic CE (red dashed line) due to the double dipole step $\Delta_{\mathrm{D}}$. (b) ICT curves of an anionic CE (blue dashed line) and cationic CE (red dashed line) featuring the same negative and positive effective pinning energies. The respective curves are shifted by $\Delta_{\mathrm{D}}$ away from the "ideal" ICT based on the respective pinning energies.

Table 1 Summary of energy band gap ( $\left.E_{g}\right)$, ionization potential (IP), electronic affinity (EA), Fermi level positive pinning energy $\left(\mathrm{E}_{\mathrm{pin}+}\right)$ and constant interface double dipole step in $\mathrm{S}=1$ region $\left(\Delta_{\mathrm{D}}\right)$ of CE series. $\mathrm{E}_{\mathrm{pin}+}$ is determined by combination of the ICT+ states in the (iii) region and the additional interface dipole step from the electrolyte dipole effect. All values are shown in unit of $\mathrm{eV}$. The $\mathrm{E}_{\mathrm{g}}$ was measured by ultraviolet-visible absorption spectroscopy (UV-Vis) and the vertical IP was from UPS. The EA was obtained by the combination of IP and $\mathrm{E}_{\mathrm{g}}$.

\begin{tabular}{cccccc}
\hline & PFN & PFNBr & P(NSO $)_{2}$ & TQm8-N & P3CBT \\
\hline $\mathrm{Eg}_{\mathrm{g}}$ & 2.91 & 2.84 & 2.84 & 1.75 & 1.9 \\
$\mathrm{IP}$ & 5.7 & 5.5 & 5.30 & 4.97 & 4.75 \\
$\mathrm{EA}$ & 2.79 & 2.66 & 2.46 & 3.22 & 2.85 \\
$\mathrm{E}_{\text {pin }}$ & 3.8 & 4.02 & 3.23 & 3.83 & 4.57 \\
$\Delta_{\mathrm{D}}$ & -0.15 & -0.21 & -0.42 & -0.15 & +0.33 \\
\hline
\end{tabular}




\section{WILEY-VCH}

Table 2 Pinning energy $\mathrm{E}_{\text {ICT- }}$ of common $\pi$-backbone acceptor (n-type) materials and $\mathrm{E}_{\mathrm{ICT}+}$ of common $\pi$-backbone donor (p-type) materials before ionic functionally. Their chemical structures and "ideal" ICT curves are shown in Fig.4S. After ionic functionally to be CEs, dependences of their work function on the work function of underlying bare substrate are shifted by the double dipole step $\Delta_{\mathrm{D}}$ as shown in Fig. 4 .

\begin{tabular}{cccccccc}
\hline $\begin{array}{c}\text { Acceptor } \\
\text { (n-type) }\end{array}$ & $\mathrm{C}_{60}$ & $\mathrm{C}_{70}$ & $\mathrm{PC}_{60 / 70} \mathrm{BM}$ & $\mathrm{BisPC}_{60} \mathrm{BM}$ & TrisPC $_{60} \mathrm{BM}$ & ICBA & $\begin{array}{c}\text { P(NDI2OD- } \\
\text { T2) [N2200] }\end{array}$ \\
EICT- & 4.57 & 4.65 & 4.35 & 4.12 & 3.95 & 4.05 & $3.93^{[43]}$ \\
\hline $\begin{array}{c}\text { Donor } \\
\text { (p-type) }\end{array}$ & $\begin{array}{c}\text { P3- } \\
\text { PrT }\end{array}$ & $\begin{array}{c}\text { P2-FQ- } \\
\text { BDT4TR }\end{array}$ & PCPDTBT & PBDTTT-CF & $\begin{array}{c}\text { APFO- } \\
\text { Green1 }\end{array}$ & $\begin{array}{c}\text { MDMO- } \\
\text { PPV }\end{array}$ & $\begin{array}{c}\text { PBDTA- } \\
\text { MIM }\end{array}$ \\
EICT+ & 4.0 & 4.3 & 4.37 & 4.45 & $4.6^{[44]}$ & $4.55^{[45]}$ & 4.5 \\
\hline
\end{tabular}




\section{WILEY-VCH}

Table of contents entry: Regular energetics at conjugated electrolyte/electrode modifier are found and controlled by equilibration of the Fermi level and additional interface double dipole step induced by ionic functionality. Based on the results, design rules for conjugated electrolyte/electrode modifier to achieve the smallest charge injection/exaction barrier and break through the current thickness limitation are proposed.

Keywords: conjugated electrolyte, electrode modifier, energetics, organic electronics

by Q. Bao*, X. Liu, E. Wang, J. Fang, F. Gao, S. Braun and M. Fahlman

Title: Regular Energetics at Conjugated Electrolyte/Electrode Modifier for Organic Electronics and Their Implications on Design Rules

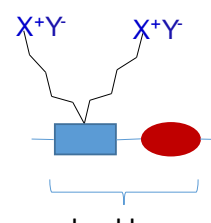

$\pi$-backbone

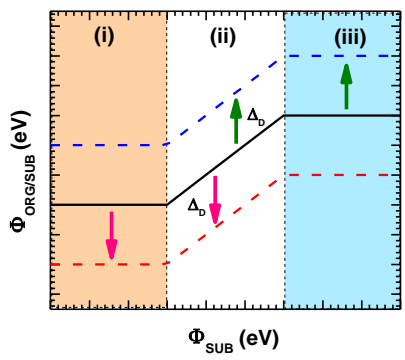

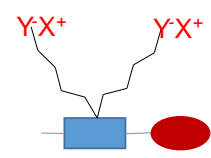

$\pi$-backbone

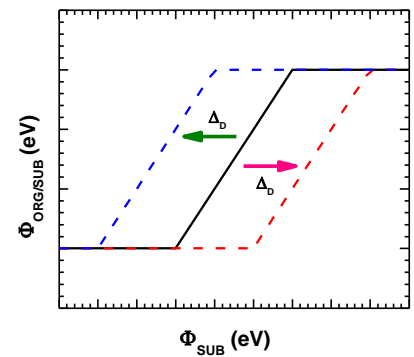




\section{WILEY-VCH}

\section{Supplementary information}

Regular Energetics at Conjugated Electrolyte/Electrode Modifier for Organic Electronics and Their Implications on Design Rules

Qinye Bao*, Xianjie Liu, Ergang Wang, Junfeng Fang, Feng Gao, Slawomir Braun and Mats Fahlman

Q. Bao, Dr. X. Liu, Dr. S. Braun, Prof. M. Fahlman

Divsion of Surface Physics and Chemistry, IFM, Linköping University SE-58183 Linköping, Sweden

Email: qinba@ifm.liu.se

Dr. E. Wang

Department of Chemistry and Chemical Engineering, Chalmers University of Technology, SE-41296, Göteborg, Sweden

Prof. J. Fang

Ningbo Institute of Material Technology and Engineering, Chinese Academy of Science, Ningbo, Zhejiang 315201, PR China

Dr. F. Gao

Biomolecular and organic electronics, IFM, Linköping University SE-58183 Linköping, Sweden

Keywords: conjugated electrolyte, electrode modifier, energetics, organic electronics

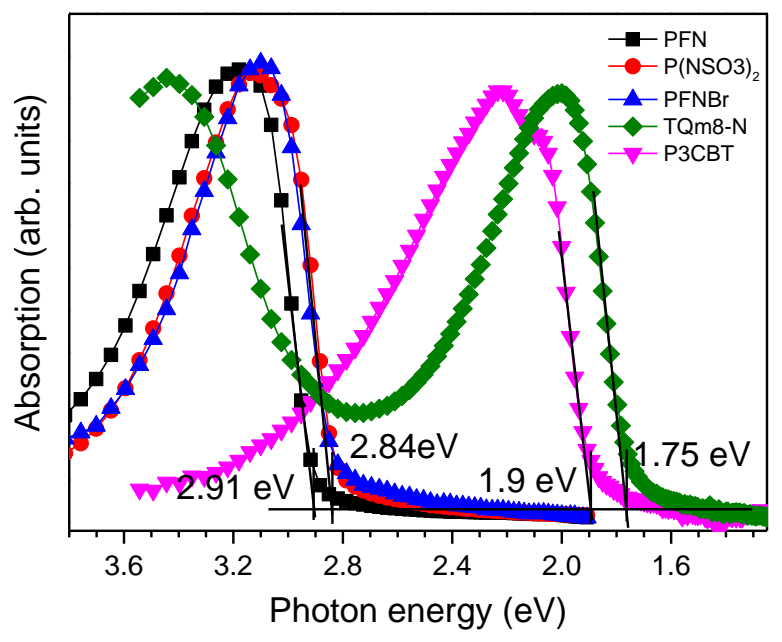

Fig. S1 UV-Vis absorption spectra of the conjugated electrolyte series. 

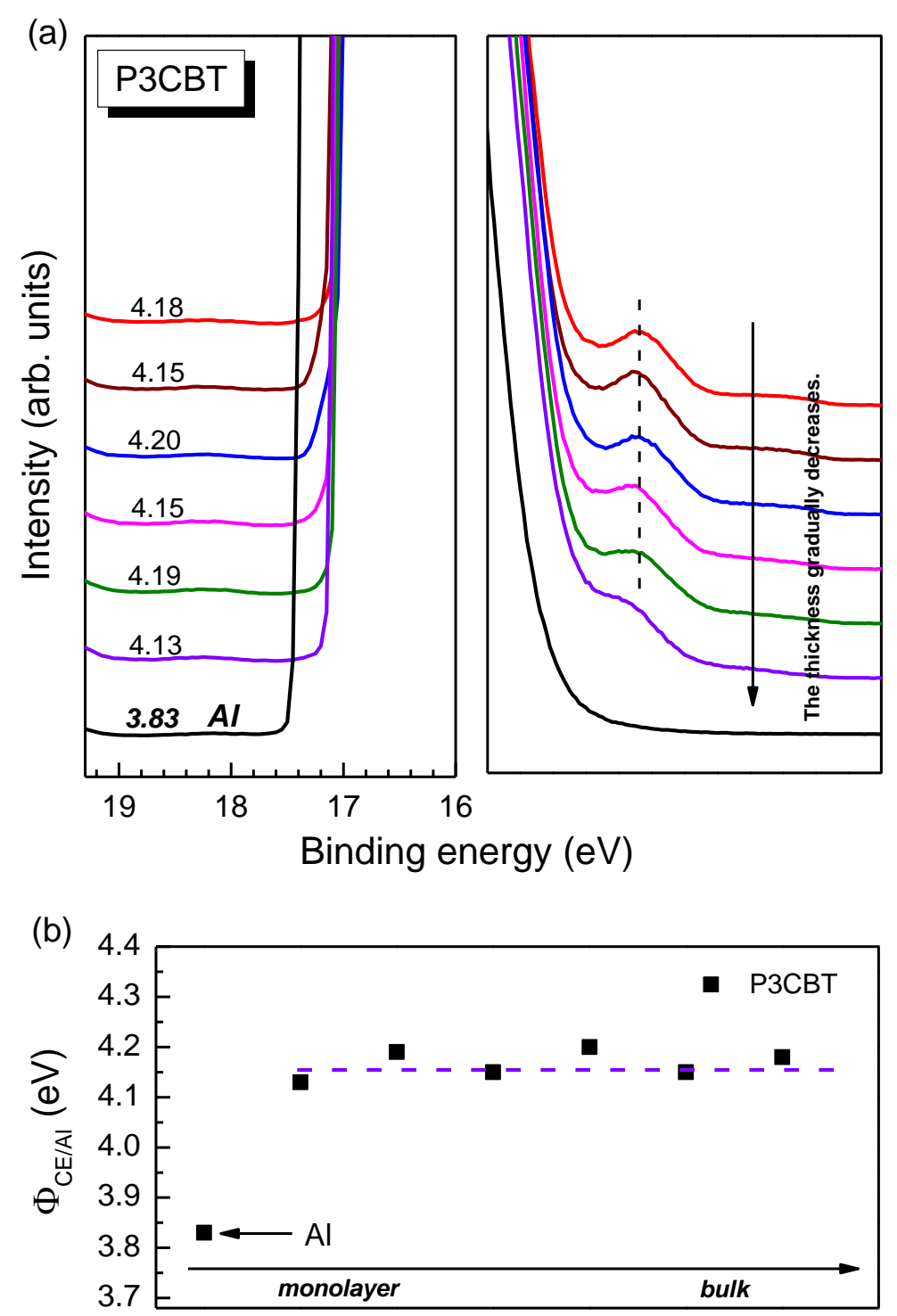

Fig. S2 (a) UPS spectra evolution both at the work function and the frontier electronic structure features of anionic $\mathrm{P} 3 \mathrm{CBT}$ coated on $\mathrm{Al}$ substrate in $\mathrm{S}=1$ region as function of thickness from bulk to monolayer. (b) Plots of the work function of P3CBT/Al interface. 


\section{WILEY-VCH}

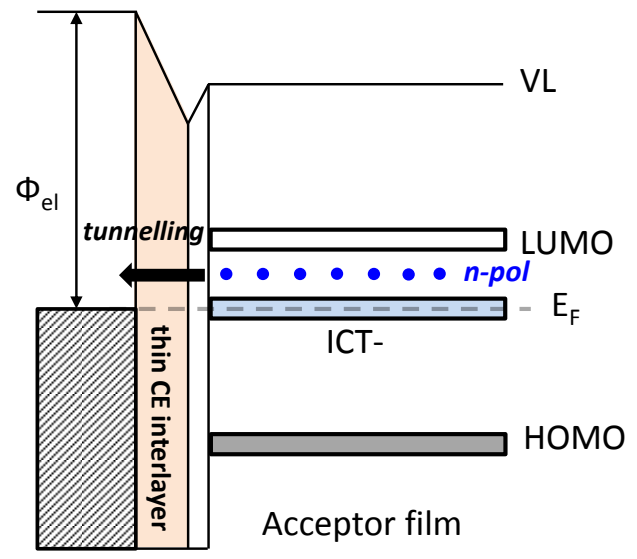

(a)

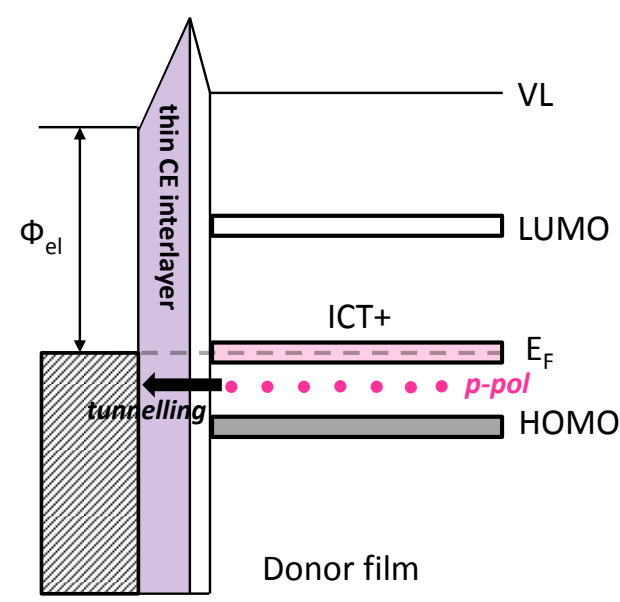

(c)

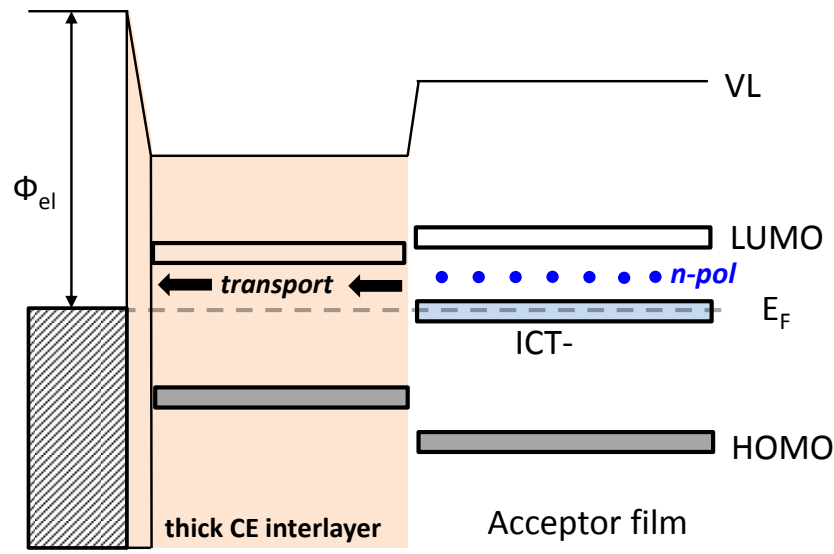

(b)

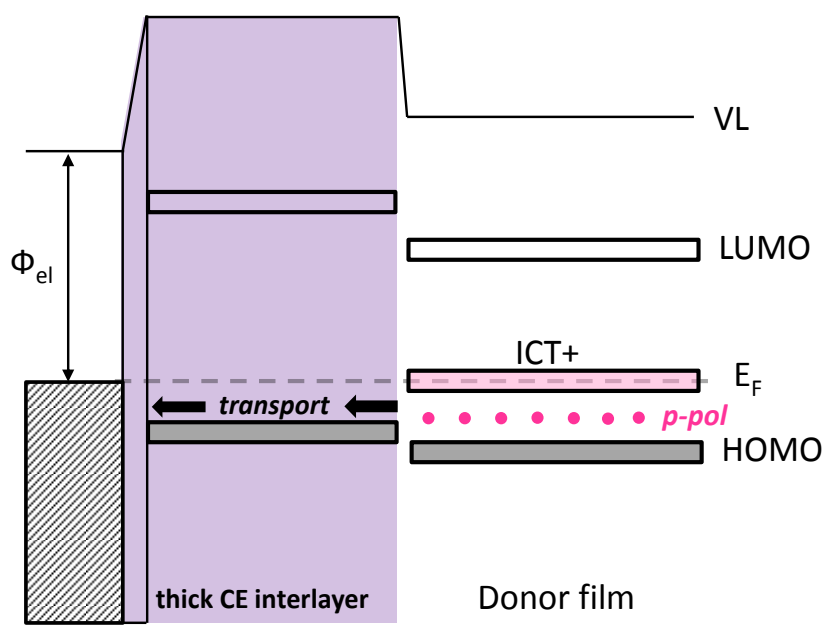

(d)

Fig.S3 Energy level diagrams for the adjacent active layer/CE/electrode interface in the case of thin[S1-3]and thick[S4-7]CE layer. (a) and (b): Cationic CE/electrode is ideal for achieving low work function resulting from the double dipole effect so as to create ohmic contact with the adjacent acceptor active layer (pinning at the ICT- state). Under operation, the n-polaron (n-pol) tunnels across the thin CE/electrode interface, whereas for the thick CE/electrode interface the n-pol follows the normal transport behavior. Analogously, (c) and (d) anionic CEP/electrode is ideal for achieving high work function in order to create Ohmic contact with the adjacent donor active layer (pinning at the ICT+ state). The thin and thick CE layer respectively corresponds to the tunneling and transport behavior of p-pol through the CE/electrode interface. 


\section{WILEY-VCH}

Donor $\pi$-backbone (p-type) materials:

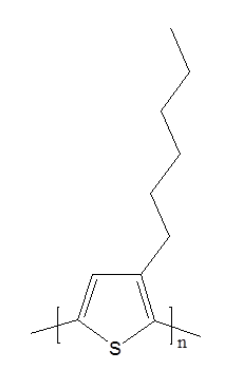

rr-P3HT

$\left(\mathrm{E}_{\mathrm{ICT}+}=4.0 \mathrm{eV}\right)$
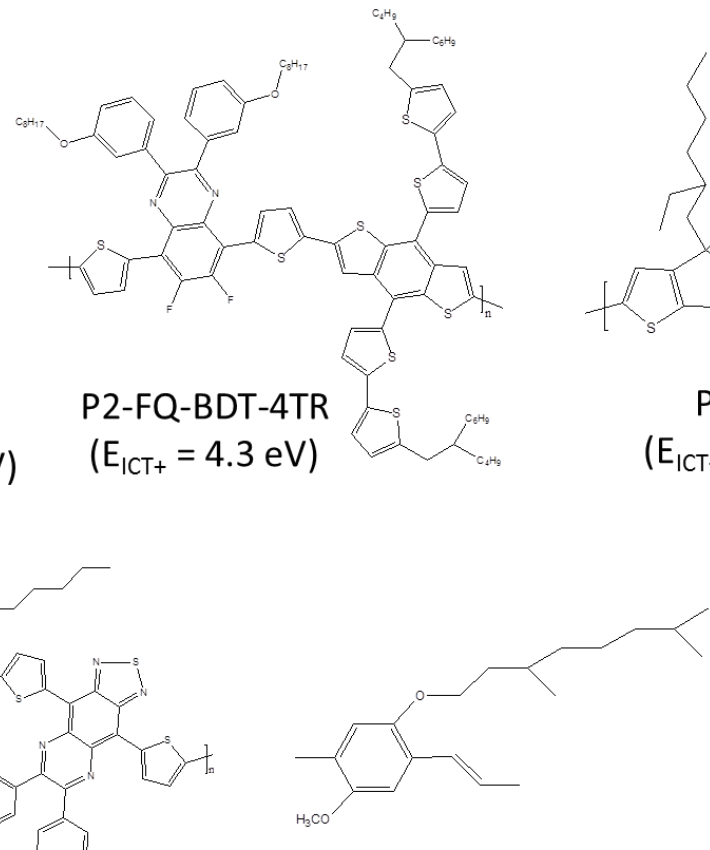

MDMO-PPV

$\left(\mathrm{E}_{\mathrm{ICT+}}=4.55 \mathrm{eV}\right)$

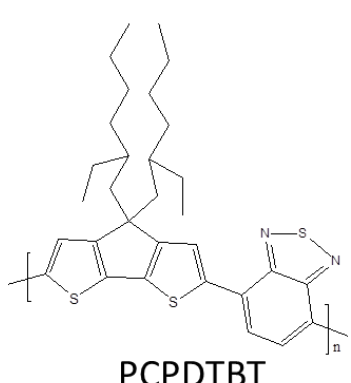

PCPDTBT

$\left(\mathrm{E}_{\mathrm{ICT+}}=4.37 \mathrm{eV}\right)$

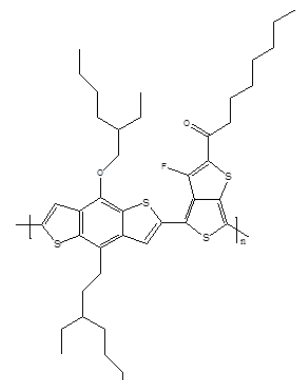

PBDTTT-CF

$\left(\mathrm{E}_{\mathrm{ICT}+}=4.45 \mathrm{eV}\right)$

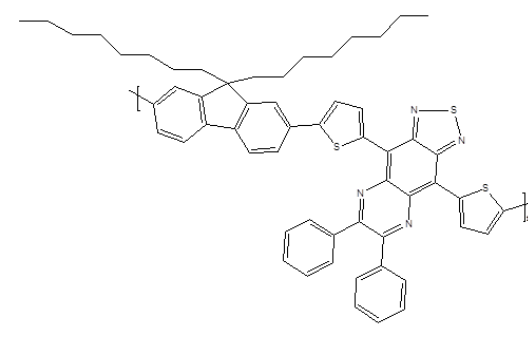

APFO-Green1

$\left(\mathrm{E}_{\mathrm{ICT}+}=4.6 \mathrm{eV}\right)$

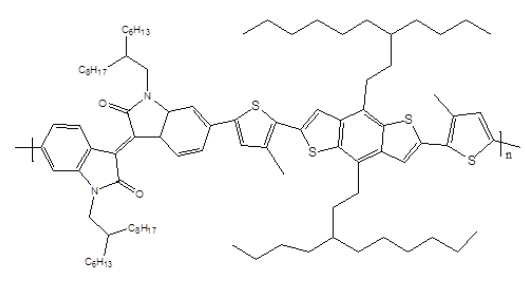

PBDTA-MIM

$\left(\mathrm{E}_{\mathrm{ICT}+}=4.5 \mathrm{eV}\right)$
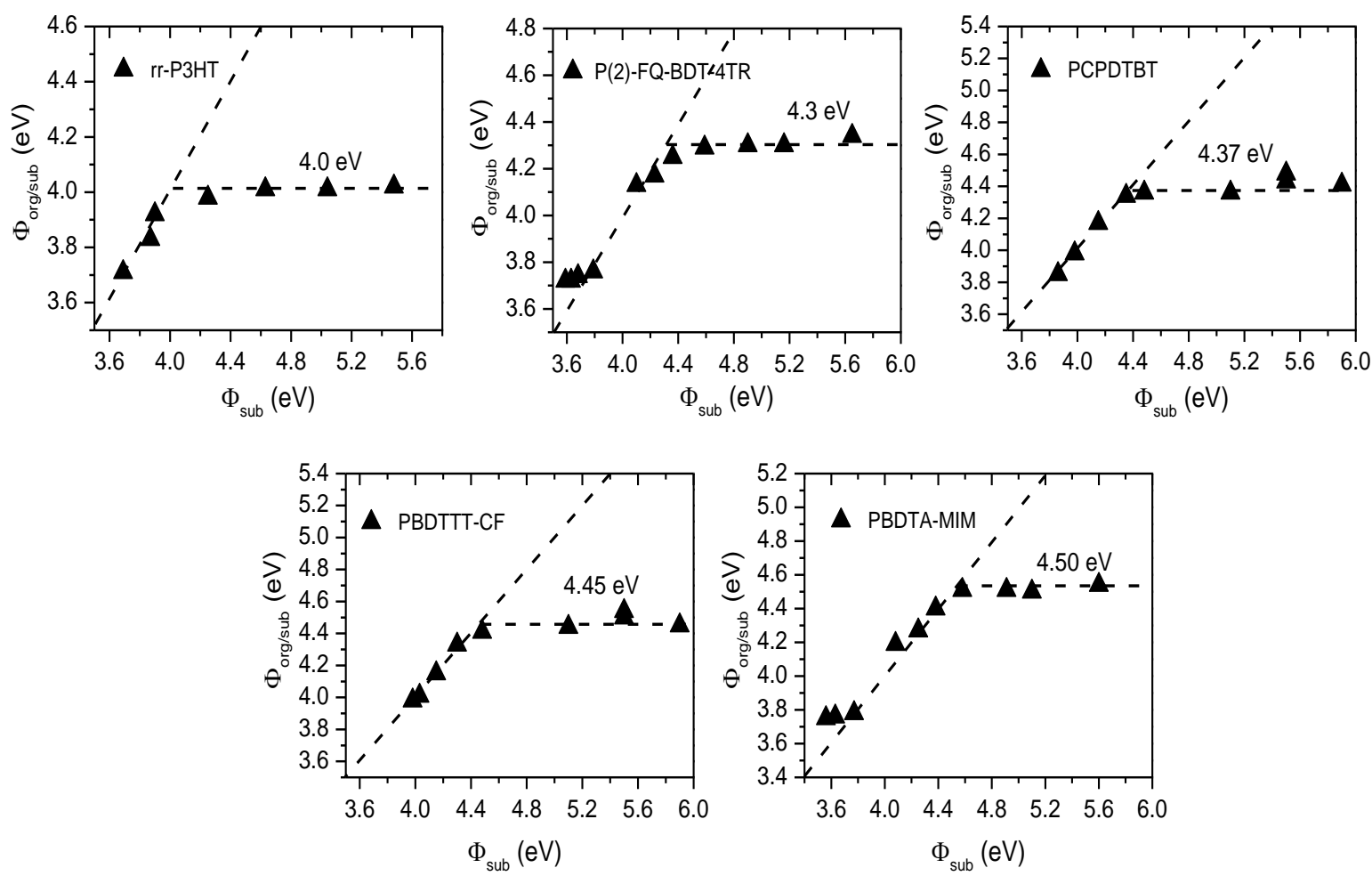


\section{WILEY-VCH}

\section{Acceptor $\pi$-backbone (n-type) materials:}

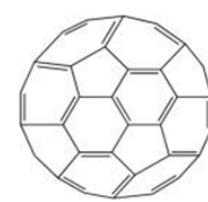

$\mathrm{C}_{60}$

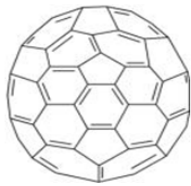

$\mathrm{C}_{70}$

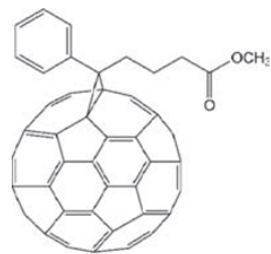

$\mathrm{PC}_{60} \mathrm{BM}$

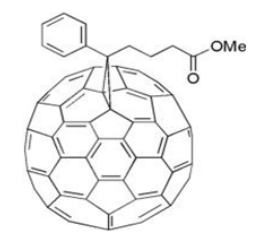

$\mathrm{PC}_{70} \mathrm{BM}$

$\left(E_{\mathrm{ICT}-}=4.57 \mathrm{eV}\right) \quad\left(\mathrm{E}_{\mathrm{ICT}-}=4.57 \mathrm{eV}\right) \quad\left(\mathrm{E}_{\mathrm{ICT}-}=4.31 \mathrm{eV}\right) \quad\left(\mathrm{E}_{\mathrm{ICT}-}=4.35 \mathrm{eV}\right)$

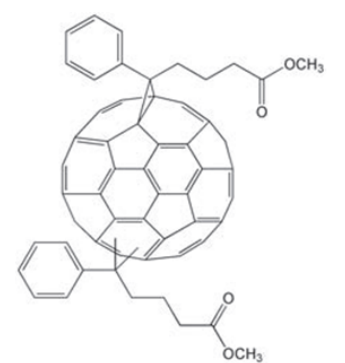

$\mathrm{BisPC}_{60} \mathrm{BM}$

$\left(\mathrm{E}_{\mathrm{ICT}-}=4.12 \mathrm{eV}\right)$

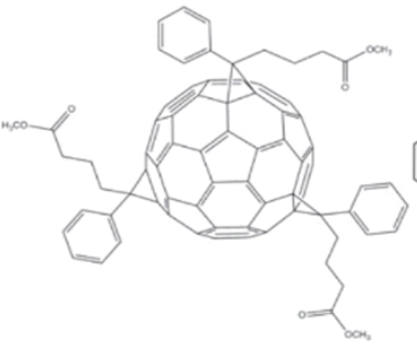

Tris $\mathrm{PC}_{60} \mathrm{BM}$

( $E_{\mathrm{ICT}-}=3.95 \mathrm{eV}$ )

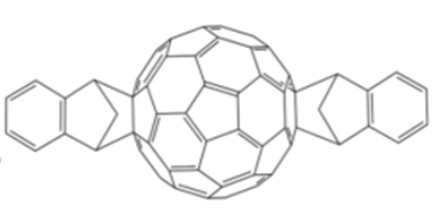

ICBA

$\left(\mathrm{E}_{\mathrm{ICT}-}=4.05 \mathrm{eV}\right)$

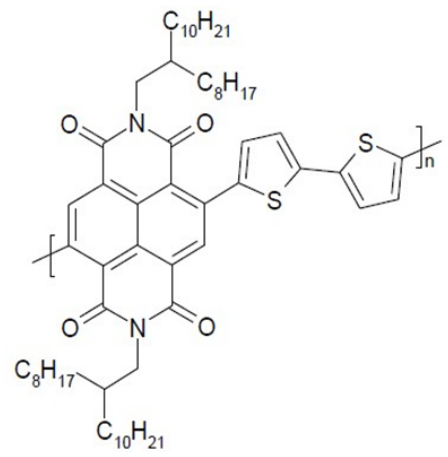

$\mathrm{P}(\mathrm{NDI} 2 \mathrm{OD}-\mathrm{T} 2)$

[N2200]

$\left(\mathrm{E}_{\mathrm{ICT}-}=3.93 \mathrm{eV}\right)$
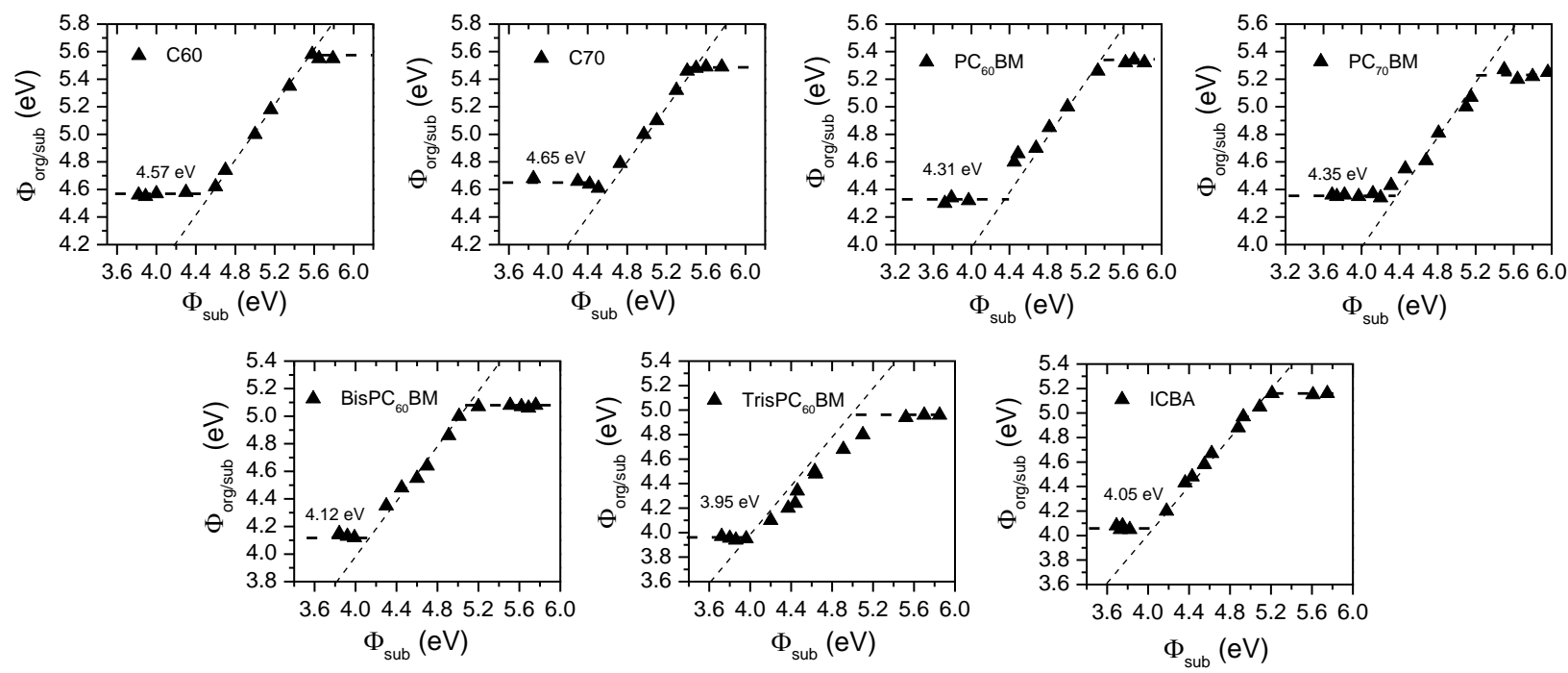

Fig. S4 Examples of pinning energies (ICT curves) of common donor and acceptor $\pi$ backbone materials [S8]. The dependence of work function of conjugated materials on the work function of underlying conducting substrates originates from equilibration of the Fermi level due to oxidation/reduction of $\pi$-delocalized backbone at interface as per the ICT model. Ionic functionality to the conjugated organic semiconductors will up- or down-shift the pinning energy with a constant interfacial dipole as discussed in the main text. 


\section{WILEY-VCH}

\section{References}

[S1] Z. He, H. Wu, Y. Cao, Adv. Mater. 26, 1006 (2014)

[S2] J. H. Seo, A. Gutacker, Y. Sun, H. Wu, F. Huang, Y. Cao, U. Scherf, A. J. Heeger and G. C. Bazan, J. Am. Chem. Soc. 133, 8416 (2011)

[S3] Liu, F., Page, Z. A., Duzhko, V. V., Russell, T. P. and Emrick, Adv. Mater. 25, 6868 (2013)

[S4] C. Li, C. Chang, Y. Zang, H. Ju, C-C. Chueh, P. Liang, N. Cho. D. S. Ginger and A. K. Y. Jen, Adv. Mater. 26, 6262 (2014)

[S5] H. Zhou, Y. Zhang, C. K. Mai, S. D. Collins, T. Q. Nguygen, G. C. Bazan and A. J. Heeger, Adv. Mater. 26, 780 (2014)

[S6] Z. A. Page, Y. Liu, V.V. Duzhko, T. P. Russell and T. Emrick. Science 346, 441 (2014);

[S7] W. Li, B. J. Worfolk, P. Li, T. C. Hauger, K. D. Harris and J. M. Buriak, J. Mater. Chem. 22, 11354, (2012)

[S8] Q. Bao, O. Sandberg, D. Dagnelund, S. Sandén, S. Braun, Harri Aarnio, X. Liu, W. Chen, R. Österbacka and M. Fahlman, Adv. Funct. Mater. 24, 6309, (2014) 